\title{
The Power Game: Power Dynamics between the Teacher and the Students in a Graduate Seminar
}

\author{
Gihan Sidky ${ }^{1}$ \\ ${ }^{1}$ College of Graduate Studies in Education- Cairo University, Cairo, Egypt \\ Correspondence: Gihan Sidky, College of Graduate Studies in Education- Cairo University, Cairo, Egypt. E-mail: \\ gihansidky@hotmail.com
}

Received: March 13, 2017 Accepted: April 25, 2017 Online Published: April 27, 2017

doi: 10.5539/elt.v10n5p179 URL: http://doi.org/10.5539/elt.v10n5p179

\begin{abstract}
This study investigated power relations in a graduate seminar on Literacy learning and knowledge acquisition. Three categories were examined in relation to ideological assumptions: students' expectations, institution's expectations, and teachers' perceptions of their roles as guided by their teaching perspectives. The study aimed at identifying how those aspects shaped by ideological perspectives influenced the interviewed teachers' viewpoints about power dynamics. It also addressed the dominance of the mainstream norms over those of the minority students coming from different cultures. The issue of voice in relation to diversity was discussed as an important factor that shaped power relations in classroom discourse. A critical perspective was adopted throughout the paper with the purpose of advocating a pedagogical stance that would encourage the empowerment of students and build upon their diversity. Through the study of field notes and audio tapes of interviews and classroom interactions, three main factors seemed to have contributed to teachers' perceptions of power relations within classroom settings. The factors were: students' expectations, institutions' expectations, and teachers' perceptions of their roles. Regarding issues of voice, participants seemed to have come to a consensus concerning reasons that might have led to persistence on teachers' part to students' conformity to mainstream norms, which they explained in terms of limitations in most teachers training in dealing with diversity.
\end{abstract}

Keywords: power, diversity, voice, ideology, mainstream norms, expectations

\section{Introduction}

This paper attempts to view power relations within the classroom through a broad lens. The class in this study is looked at as a small community that reflects existing ideologies, expectations, and perceptions shaped by the large community (Darder, Baltodano, \&Torres, 2009), (Green \& Bloome, 1997), (Crang \& Cook, 2007).

The philosophical framework which guides this study has emerged from readings, discussions, personal reflections, and concerns of issues of voice, authority, and diversity (Fairclough, 1989; Lemke, 1995; R. Scollon \& S. Scollon, 1995; Hooks, 1994; Ladson- Billings, 1994; Berlin, 1988; Delpit, 1988).

Fairclough (1989) explains how standards of rights and wrongs get established, nurtured, and sustained within a certain community in order to serve purposes of the dominant group usually at the expense of the dominated. He clarifies how those standards have been naturalized and recognized as common sense that often goes unquestioned. He also highlights the effective role common sense assumptions play in sustaining the status quo.

The same idea is addressed in Lemke (1995) where he explains how unjust social relations are justified, legitimized, and described as inevitable. Lemke (1995) claims, "discourse functions ideologically in society to support and legitimate the exercise of power, and to naturalize unjust social relations, making them seem the inevitable consequence of common sense necessity".

The relationship between ideology and power seems very crucial in the establishment and continuation of power practices. As Berlin (1988) puts it "power is an intrinsic part of ideology, defined and reinforced by it, determining once again who can act and what can be accomplished".

Scollon and Scollon (1995) state, "one aspect of the ideology of a group is whether or not it sees itself as more powerful or less powerful than some other relevant group". This seems to explain, but does not justify, how white mainstream standards get imposed probably through a feeling of superiority over minority groups. 
Given the great impact of common sense assumptions on shaping standards of people's behaviors, values, and thoughts, violating them is not always socially tolerated. Consequently, any person who dares to break those norms either consciously or unconsciously would be at the risk of being labeled, rejected, looked down to, or at the very least misunderstood. Fairclough (1989) asserts that this is more likely to happen where ideological diversity is so wide. In this case, what is taken for granted might cease to be so for everyone. This, in turn, might lead either to conformity to the dominant norms or to struggle.

The classroom as an arena where power relations are manifested between the teacher and students drove the attention of many researchers in the past three decades (Kearney, Plax, Richmond, \& McCroskey, 1984, 1985; McCroskey \& Richmond, 1983; Waltman \& Burleson, 1997). Golish and Olson (2000) investigated teacher's power, students' power and teacher immediacy. In their study power is defined as "the teacher's ability to influence students to do something they would not have done had they not been influenced" (Cited in Kearney et al., 1984).

\section{Method}

\subsection{Participants}

The participants involved in the study include a professor and sixteen students including the researcher who is a participant observer in the study. Most students in the class are Caucasian Americans; however four students are from different countries. Two students are from Canada, one is from Argentina, and one is from Egypt. As in most graduate classes, students' ages are widely varied, and so are their purposes for taking the course. Most students are teachers who take the course as part of their Master's or doctorate program.

Ann is the professor of the graduate class who has been teaching for almost thirty years. She is a powerful teacher who has great expectations from her students. Probably that was her way of empowering them. Because she is a good listener, she was keen to have every one's voice heard in class and she made it clear right from the beginning.

Charly is a high school teacher who has been teaching since 1989. He believes that the power will always remain in the teacher's hand.

Jessica is a high school teacher who has been teaching for two years. Like Charly, she believes that it is always the teacher's power and decision that count.

Cathrine is an elementary school teacher who has been teaching for thirty years. She believes that the whole language theory empowers her students.

Angela is an elementary school teacher who has been teaching for three years. She believes that, as a teacher, she has a lot of power, but she does not try to take advantage of that reality. Her way of empowering her students is through involving them in decision making.

Suzana is a native of Argentina. She teaches all subject matter in a Spanish bilingual program from first to sixth grades. She has been teaching for seven years. She cares to empower her students by trying to create a non-threatening environment.

\subsection{Research Design}

The research method used is ethnographic research. For fourteen weeks, the researcher collected data through classroom observations, and transcripts of tape recorded classes. The researcher interviewed five selected members of the class. The interviewees were chosen due to the salient points they raised in classroom discussions concerning concepts of power, voice and diversity. The approach used is a critical perspective that aims at empowering students.

The study tackles power relations in a graduate seminar among the professor and the students who come from different backgrounds and who have different years of teaching experience and various teaching approaches. Issues of voice are also examined through conversation analysis of interviewed teachers' excerpts. Discourse analysis and conversation analysis are used as qualitative methodologies in analyzing field notes of classroom interaction and the professor's and teachers' viewpoints and opinions as reflected in the interviews' excerpts regarding authority given to teachers in the class in an attempt to detect the philosophical framework that govern their opinions.

"The discourse and/or conversation analysis of classroom interaction does, however, provide a rigorous way of assessing power relations on the micro-level and as such is perfectly suited for a curriculum emphasizing empowerment." 
As Wooffit (2005) suggests the difference between discourse analysis and conversation analysis is so slim. "As a broad generalization, it could be said that DA is more interested in the context of language use, whereas CA looks at the dynamics of micro-interaction." Fairclough (1995) and others contend that the procedures for both tools are quite similar. Discourse analysis looks at the meaning of classroom interaction, i.e. the context of language use, whereas conversation analysis provides a closer look at the small details of this interaction, i.e. turn taking, interruptions, questions, prompts, and how this changes the balance of powers in classrooms (Chouliaraki, 1998; Mayes, 2010). They add, "Analysis of turn-taking and other techniques drawn from CA can be very helpful in identifying classroom roles and constructing an open, reflexive, and empowering learning environment." Fairclough (1989) also highlights how participants in a conversation control it through turn taking.

The use of discourse analysis highlighted the meanings behind classroom interaction patterns, whereas conversation analysis was mainly used to focus the attention on power relations as reflected in turn taking, asking and answering questions, interruptions, arguing, challenging the teacher's authority or surrendering to it, in other words analyzing the quality and quantity of students' talk versus the teachers' and the interplay between teacher's power and the students' and what this entails.

\subsection{Implementation}

The class is held on the basement of a college campus in the North East of the States every Thursday of spring 2011.

Classroom rituals hardly changed throughout the whole semester except for very few times towards the end of the semester. Every time, the teacher writes the agenda on the board where she specifies the different topics and tasks that should be covered for the day. The class starts with fifteen minutes of writing usually about our readings. After finishing with the writing, we usually break into small groups and discuss the readings. Then each group writes down on the board one salient point that came up in the group discussion. Finally, the whole class engages in discussing these points. Sometimes, the teacher would ask the students to bring doodles on certain topics. Analyzing the discourse behind teacher's insistence on having a fixed ritual for all her classes revealed another source of exercising power that of the imposition of a daily routine or an agenda without involving the students in such activity. The teacher made it clear from the beginning though that she would like to hear from everyone in class, however students freedom was always restricted by the space allowed for them by the teacher.

Negotiations in the Teacher's Presence and Absence:

On the first day of class everyone was so overwhelmed by the course requirements, the readings, and the assignments. The teacher's power was very obvious that day, though it was covered most of the time by the teacher's humor. However, this power was negotiated right from the beginning when Catherine expressed her dissatisfaction with having to observe two sites as part of the course requirements. She mentioned something about working as a full time teacher, having to take care of a child with special needs, and taking other courses which made it impossible for her to observe two sites (Bartlett, 2005).

The researcher started wondering how many of us had the same thoughts about the two sites, but did not dare speak them up? How many of us were relieved that Catherine was able to bring up the issue? I could tell you how many, simply by counting the number of people who chose to observe one site instead of two. All the class chose to observe one site! You might be surprised, or you might not be, if you were familiar with classroom discourse.

This happened on a graduate level where we had a bunch of supposedly sophisticated minds studying to get their Master's or Doctorate degree! Even in that privileged situation, students' power was still constrained, why? What made those students prefer to remain silent? That urges us to think of our own students, how many times do students face a situation where they hesitate thousands of times, or may be forever, before they dare to challenge teacher's authority?, Is it our power as teachers that negates students' power?, do we do that deliberately?, with what purpose?, do we do that with good intentions?, and how many of us are aware of that situation?, and is awareness enough?

Negotiation has continued for another class when Dr. Ann distributed a handout entitled "Negotiation" with a number of options concerning the two sites issue. Ann wanted the whole class to reach a consensus i.e., whether the whole class chooses to observe one site or two sites. Her main concern was fairness; she felt it was unfair for some students to observe just one site while others observe two. Again Catherine was able to articulate her opinion when she said, "I don't think this is negotiation, I think you have got to give us the freedom to choose 
either two sites or one."

The teacher seemed very willing to listen, and very respectful of her opinion. However, in spite of the teacher's willingness to listen to what her students have to say, something stronger inhibited students from speaking. It is that concept of the teacher as the sole authority within the classroom that is deeply embedded in students' thoughts.

As an illustration of this point, a comparison between the negotiation process that took place in the teacher's presence and absence might help us see the picture more clearly. The following excerpt occurred in the teacher's absence, a quick look at it summarizes the whole power issue between teachers and students, though it does not reduce its complexity.

I: to read two more books, plus the articles, plus to respond to all that, in addition to the final project...

J: Actually, has anyone seen that last ten page response paper due at the end.. that kind of reflect on all our readings?

G: Yeah

P: I forgot that one.

J: I feel that it's repetitive, like again... (The students write a weekly reflective paper on assigned readings)

G: You got to go back to the whole thing..

D: No, but it's just because there are too many projects and you have ten page reflection..

I: I am going to write a paragraph on each book. I'm not going to write more than that.

P: Hands go up.

N: Can we say that for next week, in terms of our reflective papers, can we just write a poem, draw a picture.. I know this is for some more work, but for some other people that's not. So, can we have a choice?

I: But how can you know that she will say yes?

$\mathrm{N}$ : Well, she is not here and since she left it to these three people who are..

P: No!!

\section{Class: LAUGHTER}

$\mathrm{N}$ : Either that or you could put it that she has been teaching us this is a democratic class and today she has given us the power, therefore remember what she said when we first started talking about negotiating, and whether we are gonna be on one subject or two subjects. So if we come together now and we are discussing how we feel, we should write this reaction to her.

I: May be she is expecting that... I mean she might be expecting us to be rebellious..

$\mathrm{N}$ : This is not rebelling; it's coming to a decision.

$\mathrm{C}$ : Is anyone interested in negotiating the length of the paper?

P: Yeah

G: The final ten page one?

P: Yeah

I: I wouldn't change our assignment for next week. I think that we have to negotiate what is left: the books, the readings, and the reflection. I would do the regular assignment, but I'd rather negotiate what is left.

P: I agree.

N2: Do you think we should put something on the agenda on the board next time?

This was only part of the discussion that took place in Ann's absence. Ann had to miss one class on April, $3^{\text {rd }}$, and she asked the doctorate students who were taking the course to take over. Conversation analysis of students interaction patterns revealed interesting results: classroom dynamics, turn allocations, power relations, time keeping and activities were totally different in comparison to their counterparts in the teacher's presence. The absence of the teacher allowed more space for people to speak up their thoughts, feelings, and suggestions. Many topics were raised, readings, assignments, etc. Students were definitely louder, and the sense of humor was remarkably high.

A quick comparison between the negotiation process that took place in the teacher's presence and absence 
highlights the great influence teacher's power has on classroom discussions and classroom dynamics in general. Three categories were examined in order to highlight the difference between the first and second negotiation processes: turn taking, the number of students involved in the discussion, and the quality of students' talk. First, in terms of turn allocation, in the teacher's presence usually the teacher selects the next speaker, while in her absence people felt free to self-select their turns and to interrupt the speaker more often. Second, in Ann's presence the negotiation process was initiated by one learner followed by a few comments by one or two students, while in the second time almost all class got engaged in the discussion. Regarding the quality of negotiation, while the first was very reserved and restricted to one topic, the second one was open and included so many topics.

Moreover, people who were in charge that day refused to take the responsibility for making decisions, though as it was obvious from the conversation analysis of the previous excerpt, people were encouraging them to use their temporal power. Somehow, they knew that it's a restricted authority. Interestingly enough, their refusal to be in charge of making decisions was covered by humor, the teacher's most favorite style for both exercising power and hiding power. Besides, they also tried to stick to the teacher's agenda, which the professor was keen to send, for all the classes she had to miss.

It is obvious that the presence of the teacher puts many constraints on students' freedom, no matter how the teacher claims a democratic role. Using conversation analysis reflected a tremendous change in turn allocation and turn taking patterns especially during the classes the professor had to miss. In what follows, the studentresearcher attempts to trace the factors that led to the establishment of this concept of the teacher as an authority figure in classrooms.

Students' Expectations:

Berlin (1988, p.479) comments on the concept of ideology according to Therborn, a Marxist sociologist, "ideology for Therborn addresses three questions: "what exists? What is good? What is possible?" Berlin highlights the importance of the last one as it determines "the limits of expectations" i.e., ideology in that sense indicates what could change and what could not. Concerning power relations, Berlin contends that this quality of ideology, which dictates "what is possible" determines who has the power, and sets the limits of that power. He adds, "ideology always carries with it strong social endorsement, so that what we take to exist, to have value, and to be possible seems necessary, normal, and inevitable..." He also suggests that ideology includes assumptions of how power should be distributed within a community.

Having defined ideology, let us see how much influence, if any, ideology has on shaping the interviewed teachers' expectations in this study.

When the researcher asked Jessica to comment on how she sees power exercised in this class she said,

Jessica: Throughout the whole semester in class when Ann is there... I missed the first class and I was surprised in coming to the second that we were negotiating this. I was not a sort of surprised that we were negotiating it, but I was surprised at how self-righteous the students were in saying "NO" I don't accept that. I think that you go into that as an adult and you see the syllabus and you have power, you can choose not to take that course...umm or you can take it and you are there for it dealing with the syllabus that was given to you.... We are coming to her as someone who has more knowledge in this area and who can create an environment for us.. a book list .. you know.. assignments that will help us to gain knowledge in that area.

G: So, you think it is the teacher's role to decide what's good for the students even at our age and our level?

Jessica: Absolutely

Discourse analysis here highlights that not only some teachers are not prepared to accept the idea of negotiating their power as authority figures, but some students too do not expect, get surprised, and feel a little unsettled when they meet a teacher that violates their expectations and the common sense assumptions with which they come to class. Here, Jessica views the teacher as a source of information, an expert who has more knowledge, and who knows the best way for students to acquire that knowledge. Consequently, she feels more comfortable when the teacher sticks to her role and makes decisions all the time. She also sees learning as signing a contract. If you accept its terms, you do not have the right to negotiate it. For her, it is also a matter of choice, as long as you have a choice you should not complain, "Take it or leave it".

Charley too believes that the teacher has the ultimate decision making control. And when the researcher asked him and how would you feel if Ann did the same thing?, he answered,

Charley: More comfortable 
G: More comfortable, really?!

Charley: Uha

G: Well, you have to observe two sites; you have to do this and that, no excuses,

Charley: Yeah, I would feel a whole lot more comfortable.

G: Why? Isn't it better if we for example chose to go to one site instead of two? Why then did you choose to observe one?

Charley: It's not a matter of what we are doing. If I objected to what she was saying I would talk about it anyway. I think I really feel that the way my experience of school, particularly of college has been that really every person isn't in that position by force, every person makes his own mind about everything all the time, and someone else may be by making decisions of his own limits some of your options.. only when I say okay I am gonna hand over to you this power by saying I want a doctorate degree at this university, then I'm giving her power, I am conferring really to her by accepting those terms saying I understand that those sort of the conventions of this exercise, academia, and I am gonna say okay take this power over me for the time being because I want from you, from the university this degree. So I'm going to accept your authority in granting it.

The same idea of the teacher as the only source of power within classroom discourse is expressed by Charley. To be a learner entails a loss of power for some time, until you get the degree you aspire to. For him, teacher's power somehow negates students' power. Again, the same idea of learning as signing a contract is expressed. In that sense, learning is a deal, I will submit to you for some time because I need that degree or that knowledge. Also, there is some sort of consciousness here on the learner's part. Learners come to class with certain assumptions, and obviously, those concepts affect the way students behave in class, and the way they expect their teachers to behave. Having a choice is also a criterion here, if you make a decision, you should bear the consequences. Related to the concept of choice, Charley said that there should be a difference between exercising power on a graduate level and at schools. He believes that as a secondary school teacher he should be more flexible than, for example, Ann. The reason he provides for that is that on a graduate level everyone is optionally studying, whereas schools' students are studying because it is mandated by the States law.

Suzana refuted that argument when she said,

Suzana: Some people in our class speak about having the choice of taking the class, so we need to adapt. I don't think that that is the case. Sometimes you don't have a choice, it could be the only way to get a better job for example. So it is not a matter of choice.

When I asked her, how did you feel when Ann responded to our request and canceled the ten page reflective paper?

Suzana: That was a real problematic situation. We felt so overwhelmed. It was going to affect our final paper if we didn't have enough time. It's important to focus on our final project.

G: Would you feel it's unfair, hadn't she changed it?

Suzana: I would feel that it's unrealistic. Now it's more realistic.

These different interpretations and reactions to the very same incident underline the changeability and relativity of the ideological assumptions people carry with them. As Berlin (1988) suggests, "ideology is a term of great instability". For Therborn, ideology is subject to change due to the conditions that exist at a particular time and place. It is historically specific to borrow his terms.

When I asked Angela why she didn't say anything about the two sites, she said,

Angela: I tend to be the kind of person.. okay this is something that I have to do and I accept it anyway maybe that's just what I am used to growing up... you know for power structures. And you're right there are probably tens of children who would just take it because that's what they are supposed to do, and I'm the teacher.

What Angela says about power issues asserts the role of children's upbringing in shaping their ethics and assumptions of what is acceptable and what is not in classroom discourse. This, in turn, affects their expectations and behaviors within classrooms.

Catherine points to a different ideology that might explain what encouraged her to engage in that negotiation process with the teacher, that is the ideology of the program.

Catherine: In the reading and writing program, it is supposed to be a holistic program and you are supposed to be able to negotiate. You may not get what you ask for but you can bring up the subject. 
G: So, you said that you weigh things before you speak. What is it that you weigh it against?

Catherine: Well, the biggest thing for me would be what I know to be the teacher's educational approach, and if they were holistic teachers, I would attempt to negotiate it.

Teachers have expressed different attitudes towards power dynamics within classrooms. This supports the pluralistic nature of ideology. Applying discourse analysis here unveils a number of ideologies competing within the same society, the same setting, even within the same individual. In this study, within the same group, there exist differences in people's values, viewpoints and assumptions. This pinpoints that ideology is not a singledimensioned, clear-cut concept. This diversity might result in struggle. Fairclough explains how ideological diversity could lead to social struggle which takes different shapes. Fairclough states, "There is a constant endeavor on the part of those who have power to try to impose an ideological common sense which holds for everyone... But there is always some degree of ideological diversity, and indeed conflict and struggle, so that ideological uniformity is never completely achieved." (Fairclough, 1989, p. 86)

Students come to class with certain assumptions and expectations that are framed by ideological assumptions that dictate ethics of rights and wrongs. Whenever there is a mismatch between students' expectations and teachers' behaviors, there is a possibility of struggle, discomfort, and sometimes communication breakdown.

Institutions Expectations:

Another ideology that seems to restrain teachers' behaviors within classrooms is that of the institution. Teachers represent a major source of power within classrooms, yet that power is also limited and controlled. Teachers do not work in vacuum; they work within a general frame that influences to a great deal their decisions.

This underlines the importance of sociocultural situatedness expressed by Vygotsky's idea of "mediation". According to him, peoples' ideas are shaped by the context of activities that are influenced by social and cultural environments. Therefore, classroom interaction will be affected by the preferred forms of discourse that prevail within the specific cultural setting in which the classroom exists. That dominant discourse type will, in turn, affect child's thinking (Ashton, 1996).

What Jessica said about the negotiation process that took place in class made me realize the complexity of the situation. Teachers' decisions are influenced by so many factors; they do not necessarily stem from a strong belief that this is right or wrong. What the interviewed teachers said about this issue pinpoints that teachers sometimes are forced to make certain decisions in order to meet either students' or institutions' expectations. What follows is part of the discussion that took place between the researcher and Jessica:

Jessica: I'm just surprised because maybe the teachers' decisions too.. like for example if Ann has made a decision, she would have all these things in mind. Well, I'm here.. people expect me to behave in a certain way and that's how I should behave...even if maybe she thinks she should cancel this ten page paper, but she would be concerned about what people like you for example might think of her.

G: I think so, I think this probably has to do with that.

How about you? Do you feel that pressure on you as a teacher?

Jessica: Yeah, absolutely, absolutely. One example is what I said before in class when I do use a lot of self-trash writing, and at the end I completely contradict myself and teach in the five paragraph essay as a more of a survival skill.

What Jessica says underlines the indirect restrictions imposed on the teacher. No one orders teachers, for example, to teach the five paragraph essay, however teachers know by their instinct that they should prepare students to pass the final exam. This implies that teachers do not have free hand in making decisions as one might think or hope. As Fairclough (1989) suggests, power could be exercised in two different ways, through coercion or consent. The latter is more dangerous because most of the time you do not stop to question it, it seems somehow natural. People are controlled and dominated without even feeling it.

When I asked Jessica what she thinks of that, she said,

I think it's bad.. I think it limits me.. it is insecure, if my colleagues walk by and I'm worried about their perception of my teaching ability which I think everyone is. I don't think anyone can deny that. But I think it then limits my ability to let go of the power in the classroom.. you know because probably and it will be interesting to see, I would probably turn my head around and say, hey quiet down now guys, whereas something may have been happening within the students and what they were doing. But the outside insecurity comes through and then I pull the reins getting them back a little bit. 
So, teachers' decisions concerning what and how to teach are not informed only by their own perceptions of what they think is for the best interest of the students, rather they are decisions controlled by exam requirements, institutions' policy, and other teachers' criteria of what good teaching is. The same concerns and worries have been expressed by all interviewees. Ann said:

When I started to change and started to work more with cooperative learning and small groups, it was very unsettling to me and I did have an administrator who came and said, "What's happened to you? You used to be such a good teacher. We used to stand by and there was not any noise." And the noise was coming from the group work, so there was actually a liveliness, but there was much more appreciation of the old model, so that was a real struggle for me to make that change.

Do you think you're more comfortable with the old model because it's part of the institution's expectations?

Of what power is, and what successful teaching is, yes I think so.

What Ann says about the appreciation of the old model coincides with what Shor (1992, p. 102) contends, "Education is something done to students by teachers who dominate the classroom. Education is serious when the teacher talks and students listen."

This is the model most people are familiar with and this is the model that enjoys much respect and appreciation.

Angela too expressed the same concern when she said that she gets worried when students get noisy during group work. She added that sometimes people would come and make comments such as, "what is going on here?!" Her answer is often, "Have you seen anyone off task?" She also agrees that she always has this in mind which restricts her somehow. However, she thinks that she is lucky because the school system, where she works, encourages new methods of teaching. That is why she feels she has more freedom to try things out than probably some other teachers in other places.

Institutions' policy and expectations of both the teacher and the learners restrain to a great deal teachers' decisions inside the classroom. Institutions which encourage group work, holistic perspectives and the like give teachers more freedom to apply those methods, while others control teachers' desires to try new methods and techniques, and coerce them to stick to more "traditional", teacher-centered methods.

Wertsch and Bivens (1992) contend, "We are empowered as well as constrained in specific ways by the mediational means of a sociocultural setting" (Cited in Ashton, 1996).

Shor (1992) explains, "On the job, urban and rural teachers are especially burdened by the size of their classes, the number of classes they are assigned, the short class hour, the many academic and personal needs of the students, the oppressive paperwork and bureaucracy, the absence of resources and support services, and the restrictions of required tests, texts, and syllabi. Teachers themselves lack power in their institutions, which are run from the top down. These institutions generally discourage experimenting and even punish teachers who rock the boat."

This indicates the importance of a top-down change within the whole community with all its institutions, in order to prepare the ground for the acceptance of changes in power dynamics within classroom discourse.

Teachers' Perceptions of their Roles:

Tannen (1993, p. 135) states, "power governs asymmetrical relationships where one is subordinate to another, solidarity governs symmetrical relationships characterized by social equality and similarity."

The classroom is characterized by asymmetrical relationships where the teacher holds a great deal of power and directs the situation most of the time. However, how teachers exercise power in classrooms is a decision that is affected by so many factors. Teachers' perceptions of their roles and their teaching perspectives seemed to be among the influential factors that shaped teachers' attitudes toward issues of power in this study.

Through the conversation analysis of interviewees' opinions, two main approaches have been expressed by teachers regarding issues of power. The first group expressed a more traditional approach which perceives the teacher as the sole authority in classrooms and the one responsible for decision making in class. The second group advocated a more democratic stance where decisions are co-constructed by teachers and students. Each group's perception of the teacher's role has been influenced greatly by their teaching perspectives (Benesch, 1999a).

When I asked Charley, how do you see your role as a teacher? He laughed and said,

This is going to sound terrible I know, but I think the best role of the teacher is a benevolent dictator who has the control and knows it, and makes that clear, but is doing what he thinks in the best interest of the students. 
Why do you think that your role is to dictate things?

Because I think it has to be somebody's role in the classroom. Someone has the ultimate decision making control.

And why should it be you?

As opposed to who?!

Charley's perception of his role as a benevolent dictator shapes the way he exercises power in the class. His concept of the teacher reflects his educational perspective that favors a more traditional role of the teacher as an information donator which entails the perception of students as mere recipients who have no right to participate in decision making. This notion is associated with the prevailing hierarchical nature that is embedded in the society.

He added that he did not choose that role, but he came to class to find it. For him, this is a reality that he did not create, and he cannot change. However, by not trying to change it, he somehow participated in its creation, or at least its continuation. His view reflects what Apple (1997) says, "To many people, the very idea of regaining any control over social institutions and personal development is abstract and 'nonsensical'. In general...many people do see society's economic, social, and educational institutions as basically self-directing, with little need for their participation and with little necessity for them to communicate and argue over the ends and means of these same institutions."

This same idea was emphasized by Charley when he said, "that idea of giving power simply does not exist, because by saying that okay now I will let you exercise some power, this means that I still have the power. "So, for him there is no way for change and that attempt to change centers of power in the classroom is misleading. These were among the reasons he mentioned for his preference for clear declaration and exercise of power on the teacher's part, because he thinks that hiding is insidious in some ways.

Further, Shor (1992, pp. 26-27) emphasizes the importance of previous school experiences in shaping teachers' perceptions of their roles and consequently their way of exercising power in class. She says, "As students, teachers learned early and often that to be a teacher means talking a lot and being in charge. Prior school experiences leave teachers with what Giroux (1983) called "sedimented" histories and Britzman (1986) "institutional biographies" _the values layered into professional behavior from years of traditional education"

When I asked Ann about the factors that she thinks influence teacher's authority and power in the classroom, she answered, "Power relations are affected by one's perception of his/her scholarship, presence, as well as broader aspects such as one's sense of himself/herself as a cultural being, as a gender being, etc."

I agree that all these factors influence one's power in the classroom, but does that mean that one's expertise, knowledge, and scholarship justify imposing his/her power as a teacher on students? Do these factors also make it easier for students to accept teacher's role as a taken for granted authority? Lee and Schaller (2008a, p.531) emphasize that "it was not the teacher alone who could determine the quality of relationships she established with her students"; rather, these relationships are affected by "the greater society and program context, the course, the teacher, and the students".

Is that notion of the teacher as the major source of power identical to that of being paternalistic? Being paternalistic was always justified on the teacher's part as being for the student's benefit. However, do teachers have the right to decide what is good for the students? Should it be a top down decision, or one that is negotiated? Bakhtin (1982), Benesch (1999a, 1999b), (Bartlett, 2005).

A simple illustration on this point is the example mentioned in Geisler (1994) on medical paternalism. "Mr. N, a member of a religious sect that strictly forbids blood transfusions, is involved in a serious automobile accident and loses a large amount of blood..." The question that is posed here is whether the doctor has the right to make decisions for his patients on the basis of what he thinks for their best interest, or rather to respect the patients' right in spite of the deadly consequences. Interestingly enough, I had a conversation with two of Jehovah's witnesses concerning this topic. They said that they would rather die than have a blood transfusion, and they spoke very eloquently about their reasons for having this strong belief. They also supported their arguments with verses from the bible as well as medical reasons (safety measures). When I first read the example, it did not occur to me that there would be any problem if the doctor chose to conduct a blood transfusion for the interest of the patient. However, now I do believe that they do have the right to make decisions for themselves. Does this hold true to teachers?!

One day I had to collect all my courage to express my thoughts toward a certain discussion that took place in 
class about students coming from different cultures and how they have no choice but to conform to mainstream norms in order to succeed. "But how about those who go back to their countries, will it be good for them to change?, said Maya. I was motivated by my anger, and Ann felt that I needed to say something. Maybe it was my body language that drove her attention. Neither my cultural background nor my personality helps me much to speak in public (Kurzon (1997), Nieto (2008, 2010), Tatar (2005), Jaworski \& Sachdey (1998), Harumi (1999, 2010), Goldstein (2008). However, I felt the need to react to what was said. "I really have a hard time to figure out why people here do not understand and respect other people's differences, why being different means being excluded, marginalized, or labeled, why the only option for those students should be to comply in order to succeed, to be accepted as part of the society. That was my experience, and it hurts, why should it be every minority student's experience, to give up one's identity and culture or to fail? It is unfair.

Another member of the class responded, "But isn't this the case in every country? I said, "No, if you come to my country, for example, which I believe is not the only case, people would understand that you have a different way of behaving because you are a foreigner, and they wouldn't try to make you change just to behave like they do.

Is not that exactly what Ladson-Billings (1994) refers to when she speaks about African American students whose experience in schools instilled in them a feeling that success in school means "acting white", which in turn entail that doing poorly equates "acting black".

When I asked Ann about power, she said,

I think my definition of power has to do with speaking and listening, and when I think about power I think about not only what is said but who is allowed to say it, and I think when I think about having power, I think about having the right to be heard.

How about your right to remain silent?

I think that is something I have only learnt later in life. A couple of things, I learnt that it's OK for me to remain silent. I would say within the last five years ...that I didn't need to be in charge of situations all the time. I think that helped me to understand that I needed to allow space within my room for silence.

What if I remained silent till the end of the semester, would that affect my image?

As long as I had writing from you, it wouldn't influence me. And again I think the Chinese scholar that I had last semester taught me that.. that silence does not mean lack of scholarship. Silence means something totally different, especially if there is a cultural difference, and I have to acknowledge that....

A number of studies have tried to investigate the relationship between learners' participation in classrooms and their achievement. However, most studies could not prove that students who participate more achieve better. Day (1984) has replicated a study conducted by Seliger (1983a) which indicated that "learners who initiate interaction are better able to turn input into intake". Day has conducted his study with a larger population, and concluded that there is no connection between students' participation and their achievement on an English test. Selimani (1987) has undertaken a similar study on Algerian University students in which she tried to find a relationship between learners' participation and learning. She also could not find strong evidence that interaction leads to progress. (Cited in Allwright \& Bailey, 1991).

What Allright and Bailey (1991) suggested also drives our attention to a very important fact, that silence does not necessarily mean lack of knowledge, rather it could be due to so many other reasons.

From the above mentioned studies, it seems that there is not apparent evidence that proves the relationship between students' participation in classrooms and their achievement.

What Ann said about cultural differences concerning classroom participation pinpoints a very sensitive issue that needs teacher's attention.

Sato (1982) conducted an interesting study in which she investigated the relationship between cultural traits and interaction patterns among Asian students. Her main concern was to test the stereotype of Asian students as being quieter in classrooms. She found out that Asian students took fewer turns than the others. Moreover, they took fewer self-selected turns, tended to bid more than other learners, and teachers gave them fewer turns. (Cited in Allwright \& Bailey, 1991).

This indicates that there seems to be a connection between the frequency of students' participation, patterns of participation, and students' cultural backgrounds Jaworski and Sachdey (1998), Ivanic and Camps (2001), Hirvela and Belcher (2001), Helms- ark and Stapleton (2003), Harumi ( 2010).

Why then do teachers insist on students' conformity to mainstream norms? 
Hooks (1994) claims, "Many folks found that as they tried to respect 'cultural diversity' they had to confront the limitations of their learning and knowledge, as well as possible loss of authority".

Catherine commented on Hooks claim saying,

I think that many teachers simply think that is the best way to teach. They don't know other cultures. They only know that norm and since that's the only norm they know, they agree when they hear people say this is how we will teach.

So you agree that it's a limitation in their training?

It's a limitation in their training, and as Fairclough said, it's not examining things. It's a common sense idea that not many had looked at. And if some of those teachers really looked at it in a way that makes them suddenly realize what it was doing, they might be able to change. But the more common sense something is, the more widely accepted, the more you don't see it.

When I asked Ann whether she agrees that teachers' insistence on applying mainstream norms is due to limitations in their training or not, she said,

I do, I do for sure, and I think this is the place where I am really lacking, a real understanding of cultural differences. I am just predominantly adept with white ...class kids.. and as a white middle class woman I have not had experience with a lot of diversity, and I have made some horrible mistakes in classes in terms of issues of diversity that I need to continue to work on and understand.

Charley also agrees that teachers certainly confront their lack of knowledge when dealing with diversity, a thing that he himself admits, which makes things more difficult. He also suggests a different reason for the dominance of mainstream norms in classrooms. He says that his experience with public schools made him realize how things are much more regimented than in private schools which could be one of the reasons why teachers do not encourage pluralistic approaches. He argues that in public schools some teachers have lesson plans for the whole year, and they know the date on which they are going to cover certain stage. In this case, assimilative approaches seem to be more secure and easier for them to apply.

I think the biggest reason that public school teachers prefer students conform to the mainstream norms because it's easier. I only worked in public school last year. I have worked with language schools for about six years. I came back this year. I found that part of my different attitude has to do with the different group of teachers that I worked with. For the most part they were more committed, more invested in kids' life than public school teachers as a whole, or at least this is my experience with public school teachers... ...

Jessica reported on her experience with a Saudi Arabian student who was reluctant to speak in class, and who had problems making eye contact and so on. She said that she understood that part of the difficulties he had was due to his cultural background. She said that she encouraged him to speak, but he resisted until he graduated, especially verbally more than in writing. For Jessica that was trying to push the learner's comfort zone, a practice she believes we all need to do. However, for the Saudi Arabian learner, the issue might be much more complicated than that. For him and for many other learners, it could be a question of identity.

Obviously, the problem is not only that those learners are not familiar enough with mainstream norms, but teachers too seem to be lacking the appropriate means that help them deal successfully with diversity, which I believe what teaching is all about. After all, diversity is the norm in every school, every class, and even in every individual, no matter what kind of diversity this might be. That is a great challenge that teachers need to face, and it is a two way street that both teachers and learners need to go through in order for any change to take place. Teachers' awareness is very crucial for that change; however taking an action is what makes a change a reality.

Asking students to comply to mainstream ways of thinking and behaving is called "assimilation", as opposed to "pluralism", that is a belief that encourages cultural diversity. Freeman and Freeman (1994) propose, "a closer look at history of schooling for ethnic minority groups suggests that the melting pot metaphor may not be appropriate. For one thing, not all groups have been assimilated... For another, assimilation may not be the only route to success. Cultural pluralism benefits both the nation and the various groups that contribute aspects of their heritage."

\section{Results and Discussion}

Data analysis has indicated that the concept of power is deeply embedded in ideological assumptions that influence how people view power relationships between teachers and students, and shape their views of what is acceptable and what is not acceptable in a classroom discourse. This helps in sustaining the status quo and makes change a difficult process. 
Discourse and conversation analysis used in interviews and field notes analysis, highlighted teacher's exercise of power through coercion or consent. Coercion was usually covered by teacher's humor and consent took place due to students' beliefs that the teacher should be the sole authority in the class to which they felt they had to surrender as part of an unwritten contract among teachers and students. Data analysis also demonstrated the constant change in the centers of power which were highlighted in many cases through conversation analysis that underlined a change in turn taking, posing questions, interruptions, negotiation procedures mechanisms in the teacher's presence and absence, in a nutshell; a change in both the quality and quantity of students' talk versus teacher's talk.

Data analysis pointed out that institution's expectations of both teachers and students set great constraints on power dynamics inside the classroom, and leave teachers with unsettling feelings whenever they try a new method that entails a change in the centers of power. The analysis of some of the excerpts of the interviews pinpointed this fear of trying out new methods that would challenge the institution's acceptable norms. The professor and a number of teachers expressed feeling intimidated by the judgment of their colleagues or those in charge in the institute where they work when they go against the current and try out new methods, even if these methods were effective and motivating for the students.

Teachers' viewpoints of their roles influenced to a great deal their way of exercising power and empowering their students in class. Among the roles found: 'a benevolent dictator', 'a concerned authority'. 'a facilitator', 'a mentor', and 'an adviser'. These roles are associated with different forms of exercising power, and are guided by different teaching perspectives.

Discourse analysis demonstrated that the issue of voice and silence is deeply imbedded in cultural frameworks that get instilled, developed and naturalized along years of social encounters and training, which makes it difficult for students coming from different cultural backgrounds to adopt different interaction patterns. However, they were forced in most cases to undertake that change to be part of the texture and to avoid being labeled, rejected or looked at as outsiders. The interviewed teachers seemed to agree on the reasons that might have led to teachers' insistence on minority students' assimilation. The main reason that all interviewees thought might have influenced their attitudes is that teachers did not receive enough training, if at all, as to how to deal with diversity. So it is easier to insist on conformity to the norms they are familiar with. Further, other factors, such as private versus public schools, teachers' age, teachers' perceptions of their roles (an expert, vs. a person with more knowledge), a common sense notion that was not questioned, were among the reasons mentioned in the interviews. In sum, it seems that teachers' lack of knowledge is a problem that minority students are punished for Instead of trying to provide teachers with the appropriate training they need, it is easier to ask students to give up their cultural backgrounds and their own identities. As is usually the case that has turned to be the only common sense accepted or the norm that everyone should accept without questioning.

A need to affirm and respect students' cultures as well as raise their awareness of power dynamics in the mainstream culture is recommended. Explicitness, as Delpit (1988) suggests could be the easiest and fastest way to prepare students to act appropriately within the dominant culture. And from there they might be able to change the status quo. Teachers' awareness is not enough; it is just one step on the road. The second step is to form an attitude, which in turn could lead to taking an action. A top down change should take place in order for diversity to be truly embraced and invested. However, until this becomes a reality, students' differences should be respected and invested. Their cultural identity should not be the price they have to pay for getting social and classroom acceptability and success. Empowering students has to do with respecting their opinions, and listening to what they have to say. It also has to do with having faith in students, and not being afraid of allowing their negotiations as long as they are genuine. I see that as a source of power and not the opposite. Students' active involvement in constructing the curriculum helps their learning and gives students a feeling of ownership of what they are doing which is necessary for learning.

\section{References}

Allwright, D., \&Bailey, K. (1991). Focus on the language classroom. New York: Cambridge Univ. Press.

Ashton, P. (1996). The Concept of Activity. In L. Dixon-Krauss (Ed.), Vygotsky in the Classroom (pp. 111-124). White Plains, N. Y.: Longman.

Bakhtin, M. M. (1982). The dialogic imagination by M. M. Bakhtin: Four essays. Austin, TX: University of Texas Press.

Bartlett, L. (2005). Dialogue, knowledge, and teacher-student relations: Freirean pedagogy in theory and practice. Comparative Education Review, 42(3), 344-364. https://doi.org/10.1086/430261 
Benesch, S. (1999a). Rights analysis: Studying power relations in an academic setting. English for Specific Purposes, 18, 313-327. https://doi.org/10.1016/S0889-4906(98)00011-8

Benesch, S. (1999b). Thinking critically, thinking dialogically. TESOL Quarterly, 33, 573-580. https://doi.org/10.2307/3587682

Berlin, J. (1988). Rhetoric and Ideology in the Writing Class. College English, 50(5), 477-493. https://doi.org/10.2307/377477

Chouliaraki, L. (1998). Regulation in 'Progressivist' Pedagogic Discourse: Individualized Teacher-Pupil Talk. Discourse \& Society, 9(1), 5-32. https://doi.org/10.1177/0957926598009001001

Crang, M., \& Cook, I. (2007). Doing ethnographies. Thousand Oaks, CA: Sage. https://doi.org/10.4135/9781849208949

Darder, A., Baltodano, M. P., \& Torres, R. D. (2009). Critical pedagogy: An introduction. In A. Darder, M. P. Baltodano, \& R. D. Torres (Eds.), Critical pedagogy reader (2nd ed., pp. 1-20). New York, NY: Routledge.

Delpit, L. (1988). The Silenced Dialogue: Power and Pedagogy in Educating other People's Children. Harvard Educational Review, 58(3), 280-297. https://doi.org/10.17763/haer.58.3.c43481778r528qw4

Fairclough, N. (1989). Language and Power. New York: Longman.

Fairclough, N. (1995). Critical Discourse Analysis. London: Longman.

Freeman, D., \& Freeman, Y. (1994). Between Worlds: Access to Second Language Acquisition. Portsmouth, N.H.: Heinemann.

Geisler, C. (1994). Academic Literacy and the Nature of Expertise: Reading, Writing, and Knowing in Academic Philosophy. New Jersey: Hillsdale.

Goldstein, T. (2008). The capital of "attentive silence" and its impact on English language and literacy education. In A. Luke, \& J. Albright (Eds.), Bourdieu and literacy (pp. 209-232). Mahwah, NJ: Lawrence Erlbaum.

Golish, T., \& Olson, L. (2000). Students' Use of Power in the Classroom: An Investigation of Student Power, Teacher Power, and Teacher Immediacy. Communication Quarterly, 48(3), 293- 310. https://doi.org/10.1080/01463370009385598

Green, J., \& Bloome, D. (1997). Ethnography and ethnographers of and in education: a situated perspective. In J. Flood, S. B. Heath, \& D. Lapp (Eds.), Handbook for literacy educators: Research in the community and visual arts (pp. 181-202). New York, NY: Macmillan.

Harumi, S. (1999). The use of silence by Japanese learners of English in cross-cultural communication and its pedagogical implications. Unpublished $\mathrm{PhD}$ Thesis. Institute of Education, University of London.

Harumi, S. (2010). Classroom silence: Voices from Japanese EFL learners. ELT Journal.

Helms-Park, R., \& Stapleton, P. (2003). Questioning the importance of individualized voice in undergraduate L2 argumentative writing: An empirical study with pedagogical implications. Journal of Second Language Writing, 12(3), 245-265. https://doi.org/10.1016/j.jslw.2003.08.001

Hirvela, A., \& Belcher, D. (2001). Coming back to voice: The multiple voices and identities 288 of mature multilingual writers. Journal of Second Language Writing, 10, 83-106. https://doi.org/10.1016/S1060-3743(00)00038-2

Hjelm, T. (2013). Empowering discourse: Discourse analysis as method and practice in the sociology classroom. Teaching in Higher Education, 18(8), 871-882. https://doi.org/10.1080/13562517.2013.795940

Hooks, B. (1994). Teaching to Transgress: Education as the Practice of Freedom. New York: Routledge.

Ivanic, R., \& Camps, D. (2001). I am how I sound: Voice as self-representation in L2 writing. Journal of Second Language Learning Writing, 10(1), 3-33. https://doi.org/10.1016/S1060-3743(01)00034-0

Jaworski, A., \& Sachdev, I. (1998). Beliefs about silence in the classroom. Language and Education, 12(4), 273-292. https://doi.org/10.1080/09500789808666754

Kearney, P., Plax, T. G., Richmond, V. P., \& McCroskey, J. C. (1984). Power in the classroom IV: Alternatives to discipline. In R. N. Bostrom (Ed.), Communication Yearbook 8 (pp. 724-746). Beverly Hills: Sage. https://doi.org/10.1080/23808985.1984.11678598

Kearney, P., Plax, T. G., Richmond, V. P., \& McCroskey, J. C. (1985). Power in the classroom III: Teacher communication techniques and messages. Communication Education, 34, 19-28. 
https://doi.org/10.1080/03634528509378579

Kim, S. (2011) Dynamics Under the Silence: Exploration of the Needs and Wants of Korean Students in a Large Scale English Writing Class. Unpublished PhD Dissertation, the School of Graduate Studies and Research, Indiana University.

Kurzon, D. (1997). Discourse of silence. Amsterdam, Netherlands: John Benjamins.

Ladson- Billings, G. (1994). The Dreamkeepers: Successful Teachers of African American Children. San Francisco: Jossey-Bass Publishers.

Lemke, J. (1995). Textual Politics: Discourse and Social Dynamics. London: Taylor\& Francis.

Mayes, P. (2010). The Discursive Construction of Identity and Power in the Critical Classroom: Implications for Applied Critical Theories. Discourse \& Society, 21(2), 189-210. https://doi.org/10.1177/0957926509353846

Nieto, S. (2008). Affirming diversity: The sociopolitical context of multicultural education (5th ed.). Boston, MA: Pearson Education.

Nieto, S. (2010). The light in their eyes: Creating multicultural learning communities (10th Anniversary ed.). New York, NY: Teachers College Press.

Scollon, R., \& Scollon, S. (1995). Intercultural Communication: A Discourse Approach. UK: Blackwell.

Shor, I. (1992). Empowering Education: Critical Teaching for Social Change. Chicago and London: The University of Chicago Press.

Tannen, D. (1993). Rethinking Power and Solidarity in Gender and Dominance. In C. Kramsch, \& S. Mconnell-Ginet (Eds.). Text and Context: Cross Disciplinary Perspectives on Language Study. Volumes in the series Foreign Language Acquisition Research in the Classroom.

Tatar, S. (2005). Why keep silent? The classroom participation experiences of non-native-English-speaking students. Language and Intercultural Communication, 5, 284-293. https://doi.org/10.1080/14708470508668902

Wooffitt, R. (2005). Conversation Analysis and Discourse Analysis: A Comparative and Critical Introduction. London: Sage. https://doi.org/10.4135/9781849208765

\section{Copyrights}

Copyright for this article is retained by the author(s), with first publication rights granted to the journal.

This is an open-access article distributed under the terms and conditions of the Creative Commons Attribution license (http://creativecommons.org/licenses/by/4.0/). 